American Journal of Nanotechnology 1 (2): 86-93, 2010

ISSN 1949-0216

(C) 2010 Science Publications

\title{
Abrasive Jet Polishing and its Applications in Surface Finishing
}

\author{
Zhaoze Li, Jianmin Wang, Xiaoqiang Peng, Shengyi Li and Ziqiang Yin \\ Department of Mechatronic Engineering and Automation, \\ National University of Defense Technology, Changsha 410073, China
}

\begin{abstract}
Problem statement: Single Point Diamond Turning (SPDT) is highly deterministic and versatile in producing various forms of precise optics. A typical example is the production of large offaxis aspheric mirrors and various infrared mirrors and mandrels. However, the fine periodical turning marks left in the surface critically limit its performance and they are difficult to be avoided for traditional polishing methods. Approach: This study introduced abrasive jet polishing to remove the periodical turning marks. Firstly the principle of abrasive jet polishing technique was described. Then combined with theoretical study, Computational Fluid Dynamics (CFD) simulation and process experiments, the mechanism of the material removal in abrasive jet polishing was analyzed. It was concluded that the wall shear stress of micro-abrasives is the main cause of material removal in this process. Based on this, abrasive jet polishing experiment was carried out on plane copper sample and the surface of Arrayed Waveguide Grating (AWG) which were machined after SPDT. Results: After polishing the periodical ripples on copper sample left by SPDT were removed completely and the Ra value of the sample decreases from $11 \mathrm{~nm}$ to $3 \mathrm{~nm}$. In addition, the burrs and pits on the surface of AWG Mould after SPDT are removed successfully with this technique, which solves an intractable problem in manufacture area. Conclusion: In this experiment it was found that abrasive jet polishing technique has its inimitable advantages in removing the periodical turning marks and finishing the AWG mould and it will have a broad prospect of applications in modern precision manufacture area.
\end{abstract}

Key words: Polishing process, material removal mechanism, Computational Fluid Dynamics (CFD), Diamond turning, Arrayed Waveguide Grating (AWG), manufacture area, ductile removal, surface roughness, periodical turning marks

\section{INTRODUCTION}

An overview of abrasive jet polishing setup is shown in Fig. 1. Abrasive particles and water are mixed by mechanical stirring in a tank. Then the homogeneously mixed slurry is pumped by a relatively low-pressure pump and guided through a nozzle to form abrasive jet. The jet sprays on the work piece some distance above and finishes polishing process. Finally the slurry is collected, filtrated and guided back to the tank for reuse. The work piece is positioned on a numerical control machine which can rotate and swing. The stand-off distance and the angle of the work piece with respect to the nozzle can be set by the numerical control machine. The performance of AJP process can be controlled by the components, concentration and jet pressure of the slurry and also by the relative position and angle between the nozzle and workpiece (Shorey et al., 2005). Compared with traditional polishing methods, the distinct advantages of AJP process can be given as follows (Zhang, 2007; Li et al., 2010). Firstly, because the polishing tool is slight fluid jet, the surface polished will not be affected by the distortion of the polishing pan. The mechanical and physical characteristics will not be changed and will not induce heat damage. Secondly, the slender jet will be less restricted by the shape or space of workpiece and it will be suitable for polishing various complex surfaces, especially for steep cavities. Thirdly, the recycle polishing fluid will maintain the constant temperature of workpiece and it will weed out the machining debris automatically. Finally, the slender jet will produce very small machining spot and consequently has little edge effect, which is beneficial to polish micro-optics and correct the edge figure of the workpiece.

\section{Corresponding Author: Zhaoze Li, Department of Mechatronic Engineering and Automation,} National University of Defense Technology, Changsha 410073, China 


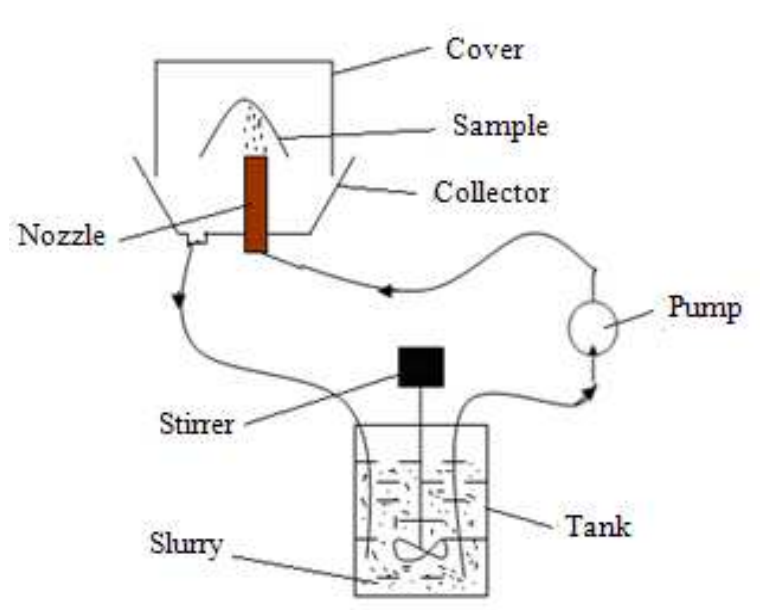

Fig. 1: Schematic setup of abrasive jet polishing

Abrasive Jet Polishing (AJP) process was first introduced by Fahnle at al. (1998) Delft University of Technology. Their research showed that it is feasible to utilize AJP process for precision optical manufacture. With AJP process, they polished BK7 optical glass and the rms value decreased from 350 nanometers to 25 nanometers. In shaping of a polished sample BK7, the surface roughness could be maintained within $1.6 \mathrm{~nm}$. Horiuchi $\mathrm{O}$ also made much research on abrasive jet polishing process. With AJP, they polished a BK7 sample. The flatness was improved from PV $=151 \mathrm{~nm}$ to $29 \mathrm{~nm}$. The surface roughness after machining was $\mathrm{Ra}=1.53 \mathrm{~nm}$ and slightly increases compared with $\mathrm{Ra}$ $=1.49 \mathrm{~nm}$ of pre-machined surface (Horiuchi et al., 2007).

Much research has been made on AJP process; however, there are little attentions been paid to the material removal mechanism. Therefore, combined with theoretical analysis and CFD simulation, the material removal mechanism of AJP process is deeply studied in this study. Then some experiments on periodical SPDT mark removal and surface finishing of arrayed waveguide grating mould are carried out.

\section{MATERIALS AND METHODS}

Abrasive jet polishing is a complicated material removal process. It contains collisions and shearing actions between the abrasive particles and work piece. According to the types of material removal, it includes brittle removal and ductile removal. In the case of brittle removal, a load is applied to the surface which causes a permanent impression on the surface.

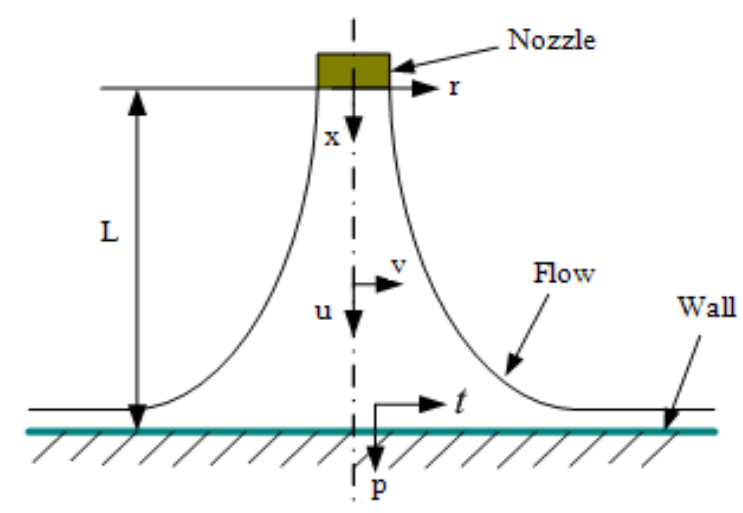

Fig. 2: Schematic drawing of parameters in AJP system

The impression grows with the increasing load and it causes the material removal at last. Ductile removal is mainly caused by shearing actions. Owing to that jet polishing belonging to low-speed jet finishing, only ductile removal occurs. Collisions result in shear stress between abrasive particles and work piece under the actions of impact press $\mathrm{P}$ and horizontal velocity $\mathrm{V}$. When the shear stress is big enough, it will remove the material of the work piece directly.

According to impact dynamics theory, AJP belongs to incompressible fluid turbulent flow motion. Its boundary layer equation can be given by Reynolds equation. For normal impingement jet, its turbulent flow boundary layer equation can be written as:

$\mathrm{u} \frac{\partial \mathrm{u}}{\partial \mathrm{x}}+\mathrm{v} \frac{\partial \mathrm{u}}{\partial \mathrm{r}}=-\frac{1}{\rho} \frac{\partial \mathrm{p}}{\partial \mathrm{x}}+\frac{1}{\rho \mathrm{r}} \frac{\partial(\mathrm{rt})}{\partial \mathrm{r}}$

The parameters in Eq. 1 are schematically drawn in Fig. 2. Here $u$ is axial velocity of the jet, $v$ is radial velocity, $\mathrm{x}$ is axial distance from the nozzle, $\mathrm{r}$ is radial distance, $\rho$ is density of the slurry, $p$ is flow pressure, and $t$ is surface shear stress. On the wall, where $x=L$ ( $\mathrm{L}$ is incidence distance), there is:

$\frac{\partial \mathrm{p}}{\partial \mathrm{x}}=\frac{1}{\mathrm{r}} \frac{\partial(\mathrm{rt})}{\partial \mathrm{r}}$

According to Eq. 2 and experiments, Beltaos and Rajaratnam (1974) gave the distributing law of the wall shear stress $t_{0}$ as:

$\frac{\mathrm{t}_{0}}{\mathrm{t}_{0 \max }}=0.18 \frac{\mathrm{L}}{\mathrm{r}}-\left(0.18 \frac{\mathrm{L}}{\mathrm{r}}+9.43 \frac{\mathrm{r}}{\mathrm{L}}\right) \exp \left[-114\left(\frac{\mathrm{r}}{\mathrm{L}}\right)^{2}\right]$

Figure 3 is the distribution of normalized wall shear stress. It shows that the shear stress t0 has 
minimum value at impingement stagnation point. center of the impingement region to the maximal Here t0 increases with the radial distance $r$ from the shear stress linearly and then decreases until zero.

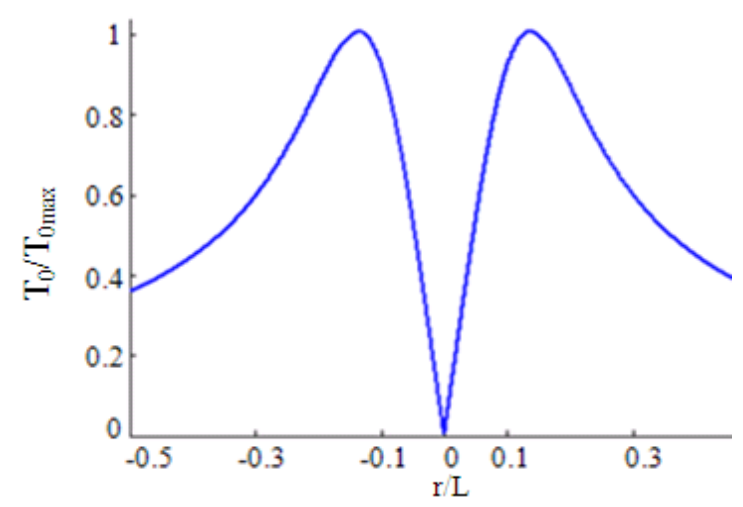

Fig. 3: Wall shear stress distribution of impact jet

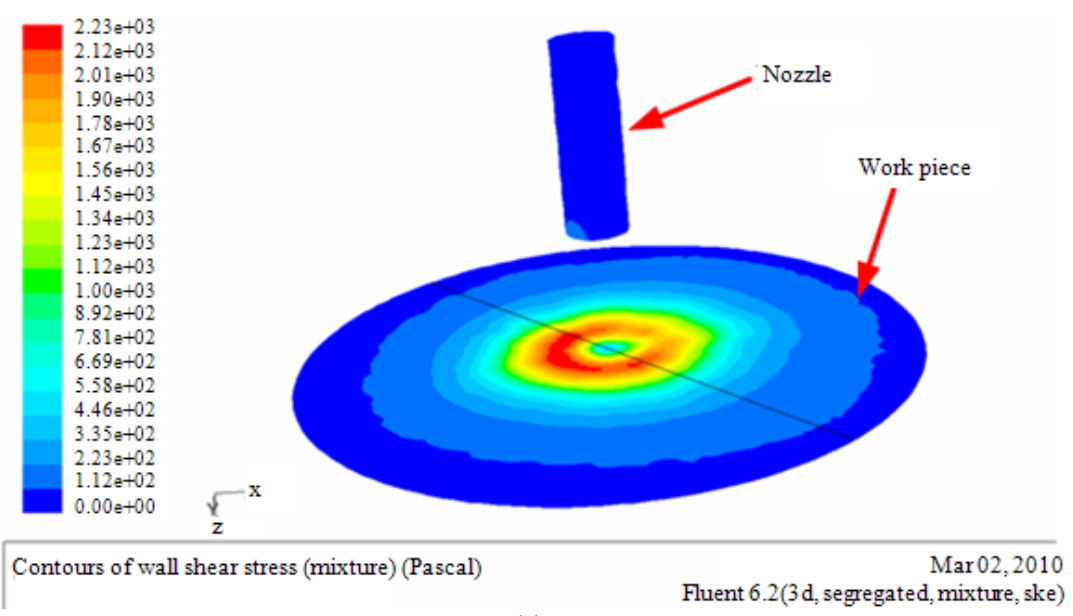

(a)

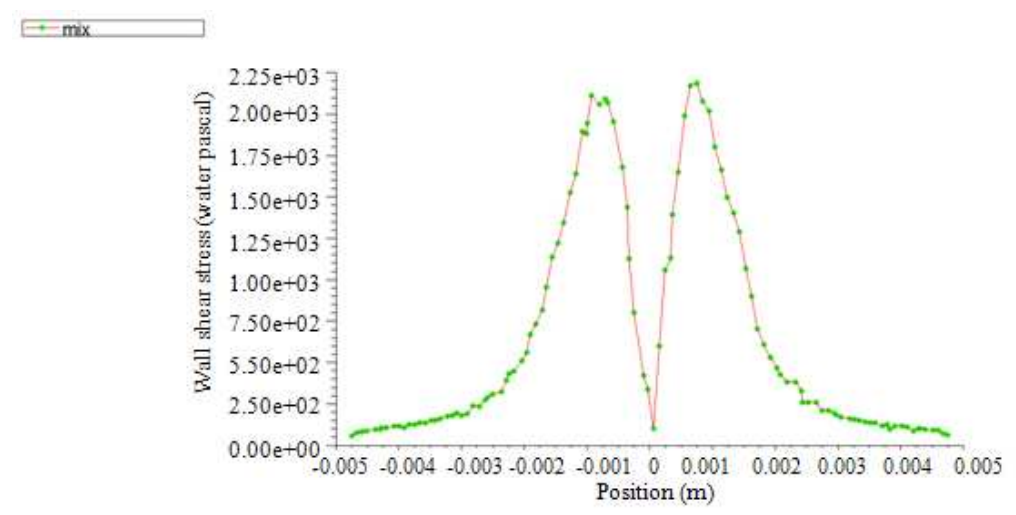

Wall shear stress (mixture) (Pascal)

Mar 02,2010 Fluent $6.2(3 \mathrm{~d}$, segregated, mixture, ske)

(b)

Fig. 4: Distribution of normal impact surface shear stress field 
For better understanding the material removal mechanism of AJP process, we introduced Computational Fluid Dynamics (CFD) simulation for jet polishing process. With FLUENT commercial simulation software, we utilized mixture model and 3D steady standard $k-\varepsilon$ viscous model. To enhance the computing precision and speed, we minimized the local grid in jet dense area. The polishing slurry was water with $5 \mathrm{wt} \%$ cerium oxide $\left(\mathrm{CeO}_{2}\right)$.

Figure 4 is the surface shear stress field distribution of workpiece impacted by normal abrasive jet. In the jet operated zone, the shear stress appears annular distributing, with a relative small value in the center of the operated zone. Then with the increasing of the radial distance, the shear stress gets firstly increasing and then decreasing. Similarly to the theoretical curve of Fig. 3, the surface shear stress distribution on one diametric direction of the workpiece shows a regular M-shape distributing, which validates that the radial shear stress of the polishing slurry is the main cause of the material removal in AJP process. With the impingement angle of $45^{\circ}$, the distribution of surface shear stress changes from annular shape to crescent shape, Fig. 5. The surface shear stress distribution on one axial direction of the workpiece is an irregular shape, Fig. 4.

To verify the analysis of material removal mechanism in AJP process, we made some experimental research on the shape of material removal with different impingement angles. Experiments got similar results with theoretical study and CFD simulation (Fig. 6). The material removal footprint is annular when the impingement angle is $90^{\circ}$.

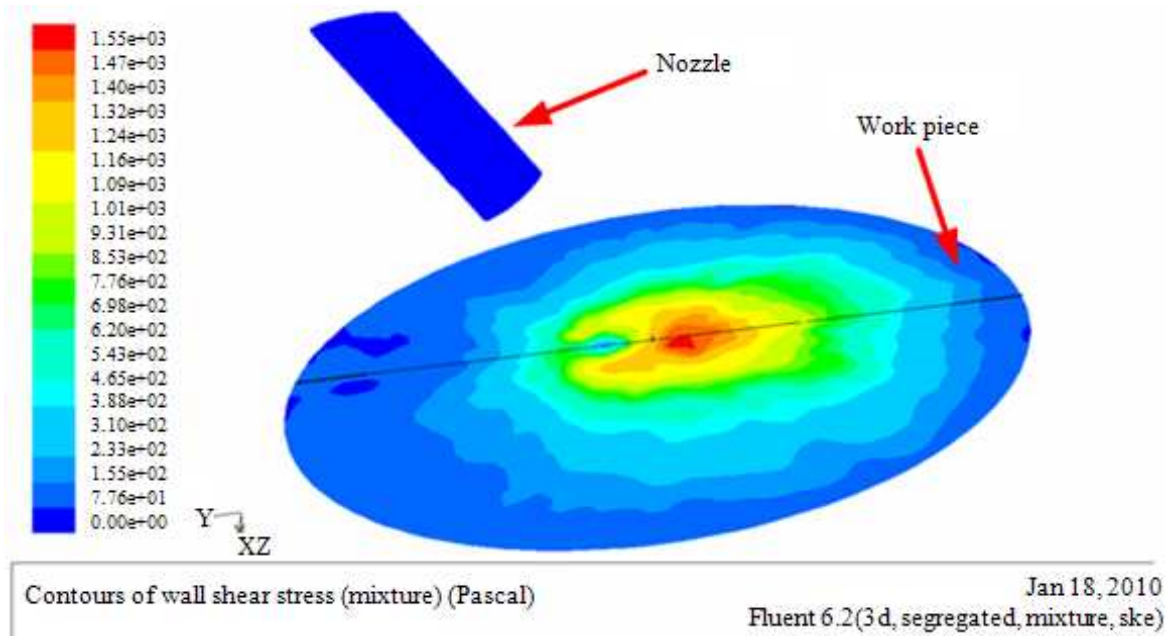

(a)

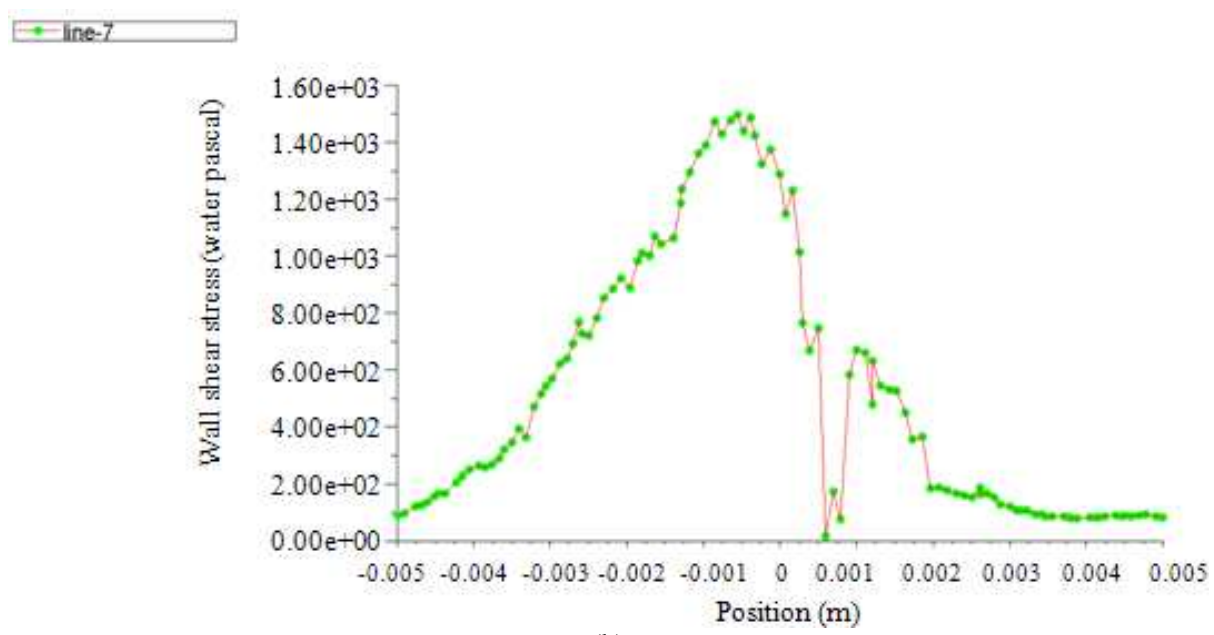

(b)

Fig. 5: Distribution of $45^{\circ}$ impact surface shear stress field 


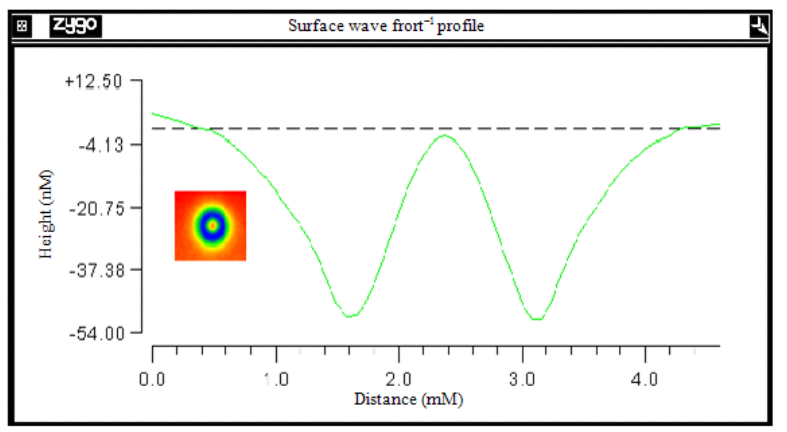

(a)

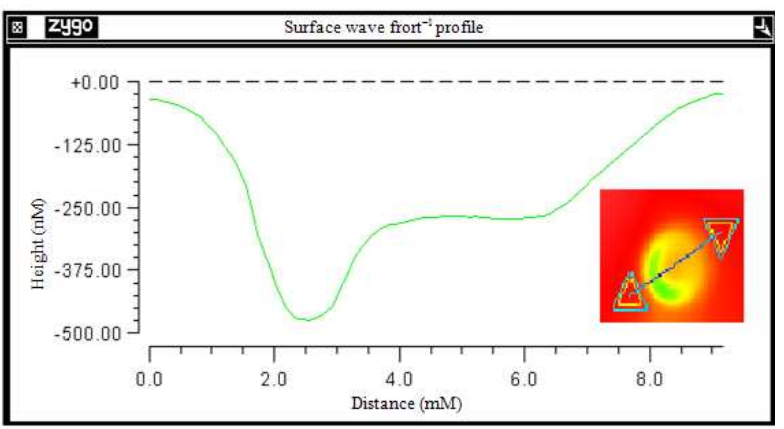

(b)

Fig. 6: Material removal footprints at different impingement angles

In the center of the polishing zone, the removed material has the least amount. The profile through the spot center is approximate a W-shape (Fig. 6a). Figure $6 \mathrm{~b}$ is the profile of material removal at $60^{\circ}$ and it performs an irregular single-peak distribution in the cross section.

Removal of periodical turning marks: Based on the study of material removal mechanism in AJP process above, we made some experimental research on removal of periodical SPDT marks. As is wellestablished, SPDT is highly deterministic and versatile in producing precise axially-symmetric forms, non axially-symmetric forms, free forms and micro-optics. A typical example is the production of large off-axis aspheric mirrors for the three-mirror astigmatic configuration (Kim et al., 2004). Other applications include various infrared mirrors and mandrels for producing the cylindrical forms of Walter-type X-ray mirrors. However, the fine periodical turning marks left in the surface critically limit its performance and they are difficult to be restrained or avoided. Obviously it is unpractical for traditional methods to remove the diamond-turning signature without destroying their forms, especially for the aspheres and free forms.

Finishing of AWG mould: With AJP process, we also made some experimental research on finishing of Waveguide Grating (AWG) mould. Because of its low insertion loss, high stability and high wavelength resolution, AWG is the most promising device for filters and multi/demultiplexers in Wavelength-Division Multiplexing (WDM) systems (Pascual et al., 2002). The manufacture quality of AWG directly affects its performance and integration level. Currently the main method for machining AWG is injection-compression molding. Traditional machining methods such as SPDT often bring disfigurements such as burrs and pits on the surface of AWG mould. Therefore, we introduce AJP process to solve these problems.

\section{RESULTS AND DISCUSSION}

Removal of periodical turning marks: In our experiment the sample was flat copper with a diameter of $12 \mathrm{~mm}$. The polishing liquid containing $5 \mathrm{wt} \%$ abrasive grains of cerium oxide $\left(\mathrm{CeO}_{2}\right)$ and other additives was used in the experiment. The grain mean diameter was $1 \mu \mathrm{m}$. The diameter of the nozzle was $1 \mathrm{~mm}$, the ejecting pressure was $0.4 \mathrm{MPa}$, the incidence distance was $10 \mathrm{~mm}$ and the impingement angle was set at $45^{\circ}$. A linear path was chosen as the scanning mode with a fixed scanning speed of $6 \mathrm{~mm} / \mathrm{min}$ and the step size was $0.2 \mathrm{~mm}$.

Figure 7a shows the original surface of the sample obtained by ZYGO New Views 200 and optical microscope. Clearly the turning marks distributed periodically and the surface roughness $(\mathrm{Ra})$ was about $11 \mathrm{~nm}$. Figure $7 \mathrm{~b}$ shows the surface after AJP process. The turning marks were cleared away completely and the $\mathrm{Ra}$ value decreased to $3 \mathrm{~nm}$. The surface can be improved further by optimizing the experimental parameters and/or controlling the material removal amount if required (Chon et al., 2006).

To estimate surface quality and validate focusing capability of the sample before and after AJP process, we introduced Power Spectrum Density (PSD) to visualize the complex spatial frequencies, which is shown in Fig. 8. Due to the existing of periodical marks, diffraction phenomenon occurs on the copper sample surface before AJP process. As is shown in Fig. $8 \mathrm{a}$ and $\mathrm{c}$, the PSD map and profile contains high spatial frequency errors. Figure $8 b$ and $d$ is the analysis of PSD after AJP process, where the diffraction phenomenon and high spatial frequency errors disappear absolutely. With AJP process, we realized the removal of turning marks on the copper sample surface. 


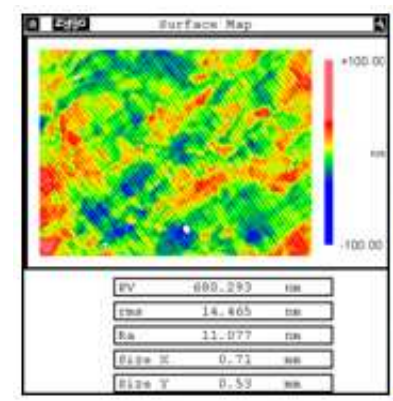

(a)
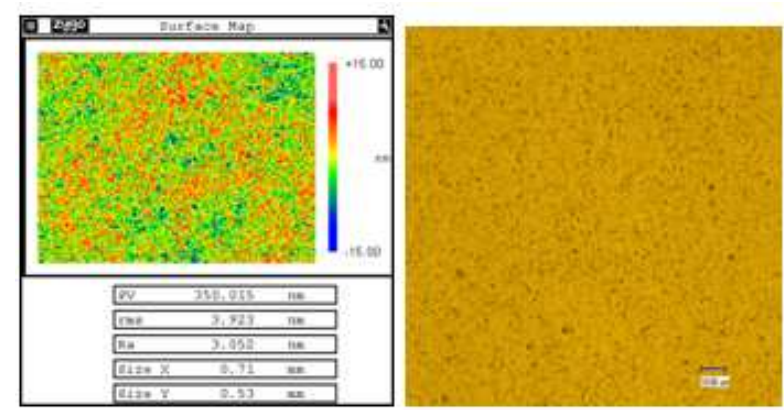

(b)

Fig. 7: Texture of diamond turned $\mathrm{Cu}$ before and after AJP

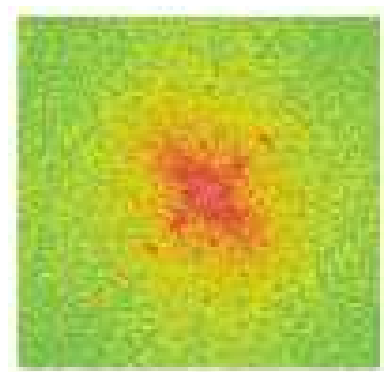

(a)

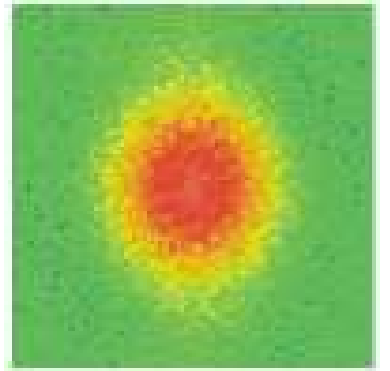

(b)

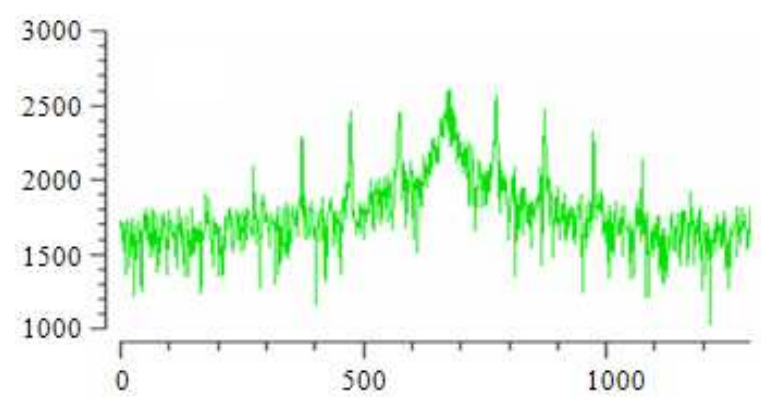

(c)

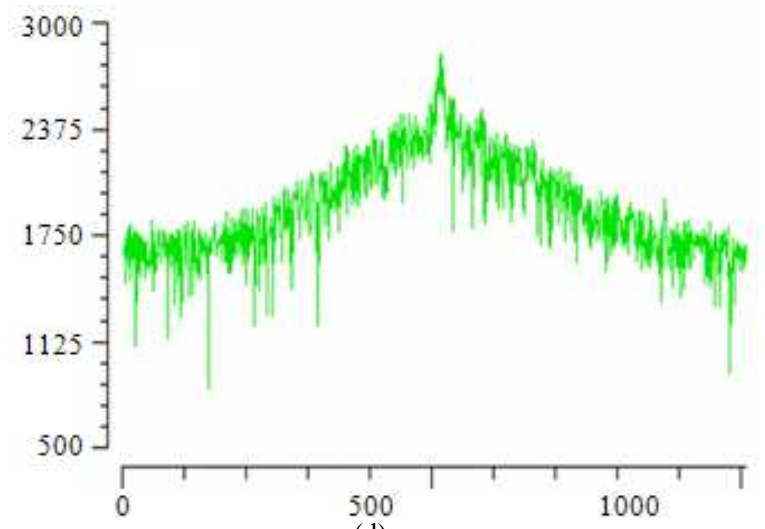

(d)

Fig. 8: Analysis of PSD Before and After AJP, (a) Spectrum map before AJP (b) Spectrum map after AJP (c) Spectrum profile before AJP (d) Spectrum profile after AJP 

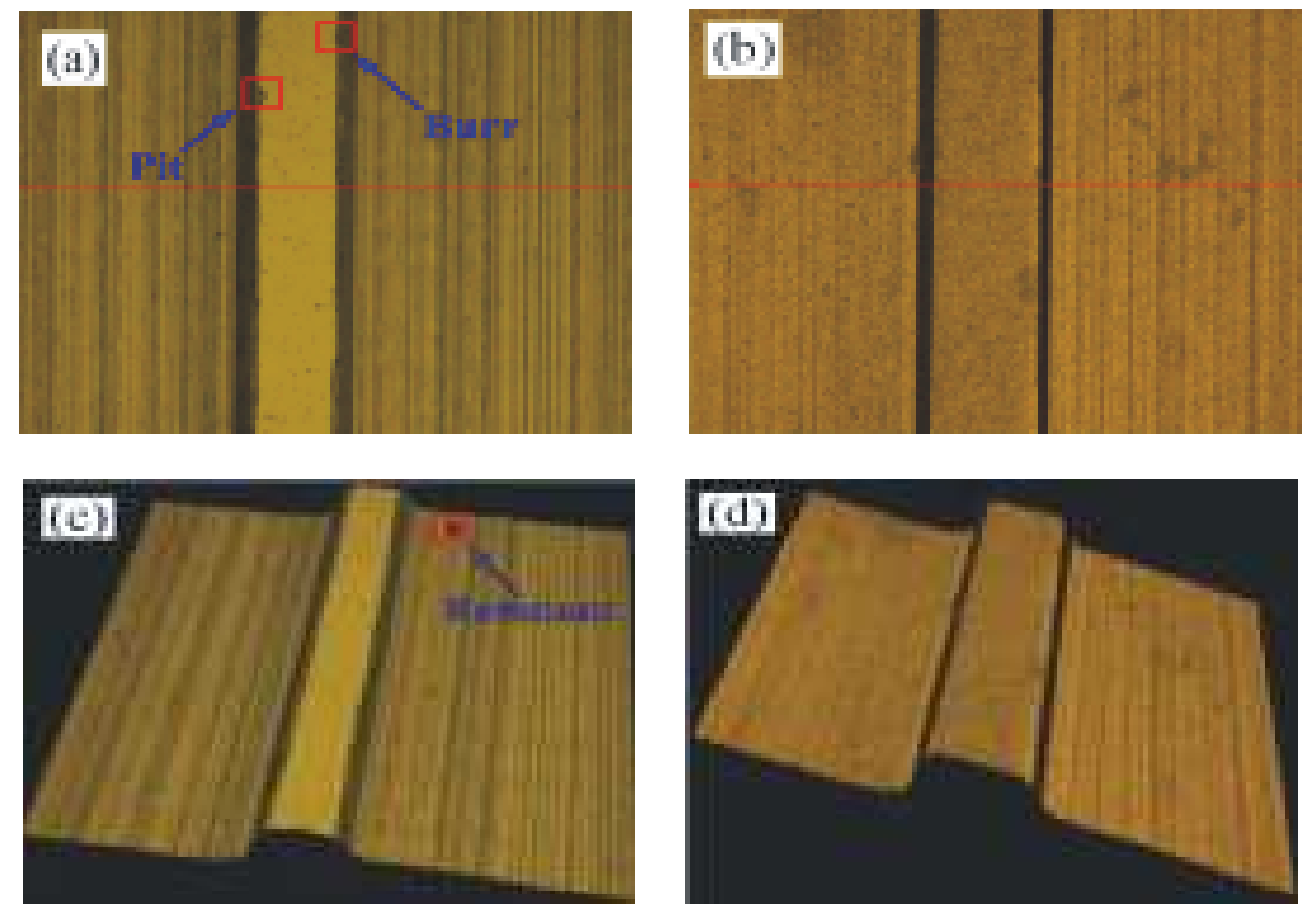

Fig. 9: Finishing of AWG Mould with AJP (a) 2D figure before AJP; (b) 2D figure after AJP; (c) 3D figure before AJP; (d) 3D figure after AJP

Finishing of AWG mould: In our experiments the sample was metal Al (6061) with SPDT micro-grating on its surface. The micro-grating was trapezoid and its top was $100 \mathrm{um}$ and height was $50 \mathrm{um}$. The polishing liquid containing $5 \mathrm{wt} \%$ abrasive grains of cerium oxide $\left(\mathrm{CeO}_{2}\right)$ with the grain mean diameter was $1 \mu \mathrm{m}$. The ejecting pressure was $0.6 \mathrm{MPa}$, the incidence distance was $10 \mathrm{~mm}$ and the impingement angle was set at $45^{\circ}$.

Figure 9 is the surface of the sample before and after AJP. It shows that the surface after polishing becomes much more clean and fine. All the burrs, pits and also some remnants left by the last working procedure were removed thoroughly.

\section{CONCLUSION}

The applications of single point diamond turning surfaces to optoelectronics products and Walter-type Xray mandrels are described in this paper. The periodical SPDT marks induce diffraction effect and stray light which limit the optical components performance and they are very difficult to be removed by traditional polishing methods. On account of this, we have introduced abrasive jet polishing to remove the periodical marks from diamond turned copper mirrors and Al (6061) AWG mould. In our experiments plane copper mirror machined after SPDT was polished with AJP process. Its surface roughness decreased from 11$3 \mathrm{~nm}$. All the diamond turning marks on the mirror have been eliminated thoroughly in the polishing process, with diffraction effect and stray light disappeared. The experiment on finishing of AWG mould was also carried out and all the burrs, pits and some remnants left by the last working procedure were removed thoroughly. The experiments results show that AJP process has its inimitable advantages in removing the periodical turning marks and finishing the AWG mould and it will have a broad prospect of applications in modern precision manufacture area.

\section{ACKNOWLEDGMENT}

This study is supported by the National Natural Science Foundation of China (Grants: 50875256) and Advanced NC Machine Tool and Fundamental Manufacture Equipment (Grants: 2010ZX04001-151).

\section{REFERENCES}

Beltaos, S. and N. Rajaratnam, 1974. Impinging circular turbulent jets. J. Hrdraulics Div., 100: 1313-1328. http://cedb.asce.org/cgi/WWWdisplay.cgi?7400855 
Chon, K.S., Y. Namba and K.H. Yoon, 2006. Precision Machining of electroless nickel mandrel and fabrication of replicated mirrors for a soft X-ray microscope. JSME Int. J., Series C., 49: 56-62. http://www.jstage.jst.go.jp/article/jsmec/49/1/49_5 6/_article

Fahnle, O.W., H.V. Brug and H.J. Frankena, 1998. Fluid jet polishing of optical surface. Applied Opt., 37: 6771-6773. DOI: 10.1364/AO.37.006771

Horiuchi, O., J. Ikeno and H. Shibutani, 2007. Nanoabrasion machining of brittle materials and its application to corrective figuring. Precision Eng., 31: 47-54.

DOI: 10.1016/J.PRECISIONENG.2006.02.005

Kim, H.S., E.J. Kim and B.S. Song, 2004. Diamond turning of large off-axis aspheric mirrors using a fast tool servo with on-machine measurement. J. Mat. Proc. Technol., 146: 349-355. DOI: 10.1016/J.JMATPROTEC.2003.11.028
Li, Z.Z., S.Y. Li, Y.F. Dai and X.Q. Peng, 2010. Optimization and application of influence function in abrasive jet polishing. Applied Opt., 49: 29472953. DOI: 10.1364/AO.49.002947

Pascual, M., P. Daniel and J. Capmany, 2002. Modeling and design of arrayedwaveguide gratings. J. Lightwave Technol., 20: 661-674. DOI: 10.1109/50.996587

Shorey, A., W. Kordonski and M. Tricard, 2005. Deterministic, precision finishing of domes and conformal optics. Proc. SPIE., 5786: 310-318. DOI: $10.1117 / 12.607456$

Zhang, X.C., 2007. Study on Magneto-Rheological Jet Polishing Technology. National University of Defense Technology. http://en.cnki.com.cn/Article_en/CJFDTOTALJSYZ200712050.htm 